\title{
Reading aloud in jargonaphasia: an unusual dissociation in speech output
}

\author{
Carlo Semenza, Lisa Cipolotti, Gianfranco Denes
}

\begin{abstract}
A patient is described who showed several dissociations between oral and written language processing after bilateral retrorolandic vascular lesion. Dissociation was firstly between abolished auditory comprehension and preserved written comprehension and then involved confrontation naming, clearly superior in the written modality. The third striking dissociation involved oral output; spontaneous speech, although fluent and well articulated, consisted of neologistic jargon, while reading aloud was clearly superior though not perfect. Data are discussed with reference to a cognitive model of word processing. The pattern of dissociation in word production may be due to a failure in retrieving the phonological word form from the semantic system.
\end{abstract}

There have been occasional reports of patients whose reading aloud or writing or both appear better preserved when compared to wellarticulated but otherwise disrupted or incoherent oral naming and spontaneous speech. ${ }^{12}$ According to the Wernicke-Lichtheim model, the only case in which such a dissociation should occur is in transcortical aphasia, where the centre for concepts is thought to be cut off from sensory areas. Reading aloud (or repetition) may be accomplished by an intact connection between sensory and motor areas. The model, however, cannot explain a patient featuring this behaviour but in whom comprehension of written language is present. This report provides an explanation of such a pattern.

Department of Psychology, University of Padova

C Semenza

Neurologic Clinic, University of Padova G Denes

Department of Psychology, University College, London L Cipolotti

Correspondence to: Dr Denes, Clinica Neurologica, Via Giustiniani, 5, 35128-Padova, Italy. Received 17 August 1990 and in final revised form 16 May 1991.

Accepted 27 June 1991

\section{Case report}

A 65 year old right-handed housewife with five years' education and no history of disorders in reading acquisition was admitted in November 1985 to the department of Neurology, University of Padova, for evaluation and treatment of language disturbances of sudden onset. Ten months previously she had been admitted to a medical ward of the same hospital because of a sudden onset episode of lack of muscle tone to both legs, interpreted as a drop attack. No aphasic signs were reported in the medical records. A CT scan (January 1985) showed a pattern of cerebral atrophy, mainly supratentorial, with enlargement of the lateral as well as the third ventricles. A large hypodense lesion occupied the left sylvian region, including the frontal lobe. Posteriorly the lesion showed fuzzy limits extending to the parietal lobe, both superficially and deeply. On discharge she was free of symptoms and, according to relatives, her language production and comprehension were normal.

On the second admission, neurological examination was normal apart from some neuropsychological signs. A second CT scan (December 1985) was essentially unchanged on the left side while a new area of hypodensity affected the right parietal lobe. A nuclear magnetic resonance (NMR) scan showed numerous artefacts because of her poor collaboration, but the resulting pattern was consistent with that observed on the CT scan (figure).

GENERAL NEUROPSYCHOLOGICAL

EXAMINATION

The patient was oriented in time and place. On the Edinburgh handedness inventory for righthandedness she scored 10/10. Her collaboration in the tests was good except when auditory tests were performed. Initially she showed a severe anosognosia which gave way to a partial awareness of her deficit over a few days. On the Raven matrices (RCPM 47) her score was $18 / 36$ (this score corresponds to the mean of an unselected population with left hemisphere

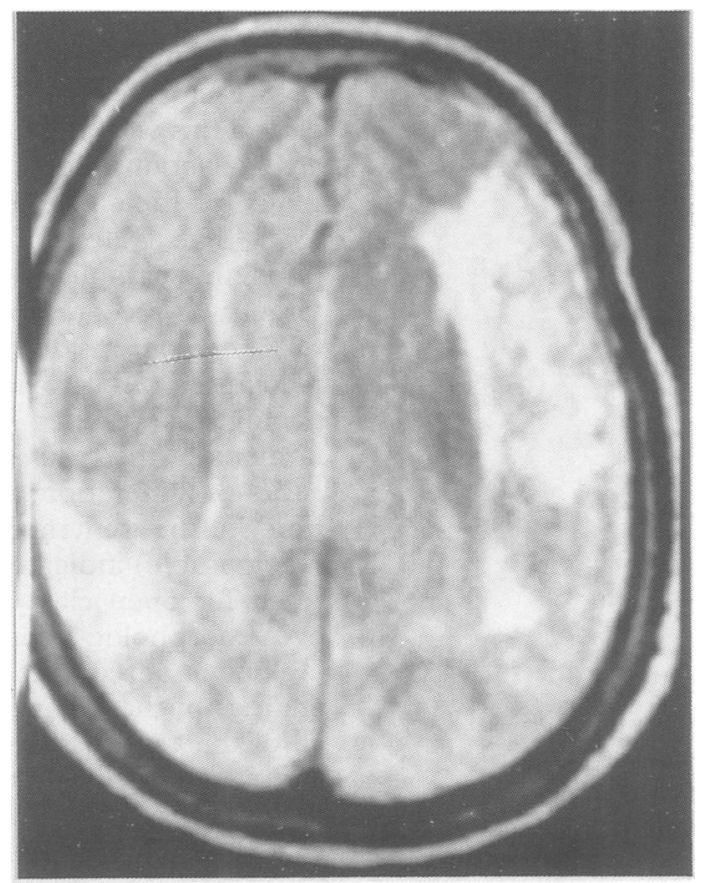

Figure NMR scan, TI weighted (TR200, TE20) showing bilateral lesions larger on left. 
damage $\left.^{3}\right)$. Her spatial span, as measured with the Corsi block Tapping Test was 4 (normal mean score $=4.7 ;$ SD 0.95 ). No evidence of visual agnosia or prosopagnosia was detected. She did not show neglect in either the visual or tactile domain. Drawing (spontaneously and on copy) was fairly good. Mild signs of buccofacial and ideo-motor apraxia were present.

Sound awareness and Recognition-She showed extremely severe auditory impairment that affected the perception of both verbal and nonverbal sounds and noises. She did not react when called, no matter how loudly, and strong sudden noises appeared to have no effect on her. She was completely unable to match a meaningful sound to the corresponding picture. A peripheral deafness was excluded by audiometric studies.

Audiometric studies-Pure tone audiometry was not available given her inability to understand the procedure. Auditory brainstem evoked responses (ABR) were obtained with alternate polarity clicks at different intensity levels (rate 21/sec; filters 200-3000 Hz; epochs 2048; Amplaid MK6); the threshold for clicks was $15 \mathrm{db} \mathrm{Hz}$, bilaterally. The middle latency response (MLR) showed normal shape and latency of the major waves $(\mathrm{Pa}=33.50 \mathrm{msec})$ compared with a sex-age matched control group. Slow vertex responses (SVR) showed normal shape and latency of $P_{1} N_{1} P_{2} N_{2}$. A study of the P300 wave was not possible because she was not able to obey the orders.

\section{LANGUAGE EXAMINATION}

Spontaneous speech - The patient's spontaneous speech was totally unintelligible and fitted the clinical pattern of neologistic jargon aphasia. Out of a sample of 752 word-like segments, $63 \%$ were real words and $37 \%$ were non-words (segmentation boundaries were established by three independent judges, on the basis of prosodical cues). Just over a quarter of the real words belonged to the open class and the rest to the closed class. The proportion of open class items was therefore more than five standard deviations below the mean $(40.25$; SD 2.34) for Italian subjects with low educational level. ${ }^{4}$ The analysis of non-words revealed $34 \%$ phonemic paraphasias, $13 \%$ neologisms whose target was recognisable from the context, and $53 \%$ neologisms whose target could not be recognised. About half of the latter type of neologisms resulted from perseverative phenomena of the type described by Buckingham $e t a l^{5}$ as alliteration and assonance. The position in the sentence and the target (when recognisable) indicated that neologisms substituted for open class items. A relative control over morphology could be demonstrated by looking at agreement between articles and the endings of the following nouns or neologisms; all of the case endings were proper inflections and were correct for both number and gender. Except for a few dubious cases all phonotactic rules for Italian were respected.

Oral and written naming - The patient could not recite any of 21 letters or numbers from 1 to 20; but on the same tests her written performance was flawless. Oral naming for pictures belonging to different semantic categories was nearly impossible ( 1 out of 40 for pictures, 1 out of 10 for real objects, and 0 out of 12 for body parts). Written naming was fairly well preserved: she was able to write the correct name for 19 out of 20 pictures (taken from the collection of 40 pictures used for oral naming) and eight out of 10 objects (same objects used for oral naming). In oral naming tasks most of the errors consisted of neologisms while in written naming tasks the few errors were of single grapheme omissions or substitutions, resulting in an identifiable nonword. She was also able to write sentences in answer to questions.

Reading performance-Contrary to spontaneous speech, her reading aloud was almost unaffected. Her letter naming was correct for the whole Italian alphabet (21 out of 21), though letter sounding could not be evaluated because of her inability to understand the task. The patient was asked to read aloud 15 syllables composed of CV (5), VC (5), or CCV (5). She read correctly 12 out of 15 syllables, all 3 errors being on VC: ac was read as /ak/, ot was read as /as/, us was read as/us/. She was asked to read a list of 185 words taken from a battery currently used in our unit. Normal readers with at least 5 years' education are expected to perform at the highest level in this task with the exception of very occasional errors. The stimulus features varied in the list included word class (nouns, verbs, adjectives, and function words), frequency, concreteness, and length. She correctly read 162 out of 185 words. The words were read promptly, and no relationship was found between stimulus length and reading time. A summary of her reading performance is given in the table. Most of the errors were of the visual type (for example, brocca read as boca, pertanto as pertando). She made four errors out of 20 on reading words with unusual stress position; the errors, however, did not involve the stress (mòrbido read as nòrbido). The same list of words was presented in a repetition task: the patient was unable to repeat even a single phoneme. A list of 123 pronounceable nonwords of varying length $(4,6,7,8,10$ letters) was made by changing one or two letters in the

Table Summary of patient's reading of Italian words

\begin{tabular}{lcc}
\hline & No presented & No correct \\
\hline Concrete nouns (HF) & 15 & 13 \\
Concrete nouns (LF) & 15 & 12 \\
Nouns with unusual stress & 10 & 8 \\
$\quad \begin{array}{l}\text { position (HF) } \\
\text { Nouns with unusual stress }\end{array}$ & 10 & 8 \\
$\quad$ position (LF) & 15 & 13 \\
Abstract nouns (HF) & 15 & 12 \\
Abstract nouns (LF) & 15 & 14 \\
Proper names & 15 & 14 \\
Functors (HF) & 15 & 14 \\
Functors (LF) & 15 & 13 \\
Adjectives (HF) & 15 & 14 \\
Adjectives (LF) & 15 & 14 \\
Affixed verbs (HF) & 15 & 162 \\
Affixed verbs (LF) & 185 & \\
Total & & \\
\hline
\end{tabular}

HF = high frequency; LF = Low frequency. 
initial, medial, or final position of high or low frequency words. Comparable normal readers for education tend to perform at the highest level in reading this list and never make more than five or six errors, probably due to the fact that Italian orthography is normally transparent. She was able to read correctly 88 nonwords $(71.5 \%)$. All errors were visually related to the non-word target and consisted mainly of substitution of a single letter of the target nonword (for example spiranza read as spinanza or omission of a letter (ignibile as igibile). Six errors resulted in real Italian words (for example amavezza as amarezza). The remaining 29 errors were other non-words. No length effect was noted.

Oral and written language comprehension-She was completely unable to match spoken words to the corresponding pictures ( 0 out of 20 ) or to indicate body parts ( 0 out of 12$)$ or colours (0 out of 8 ) from a multiple choice array. She did, however, show a much better performance in reading comprehension of the above material. She was able to match written words to pictures (20 out of 20) and indicate on written order body parts (11 out of 12) and colours (seven out of eight). On a written version of the token test (untimed presentation) her score was 20/36 (no normative data are available for the written version: in the oral version this score would correspond to a moderate impairment ${ }^{6}$ ). Furthermore, she was able to detect semantic anomalies-for example, crows are fruits - in written sentences (10 out of 10) and to match written words to semantically related pictures in a multiple choice setting (for example, word: shortsighted, picture: glasses; 10 out of 10 correct).

\section{Discussion}

This patient's severely disturbed speech output and auditory comprehension contrasted with her good performance for written material: written comprehension. Her written naming and reading aloud were, if not flawless, clearly superior to other language skills. The dissociation on the productive side is difficult to explain in relation to neurological models of language processing ${ }^{7}$ in which reading aloud and reading comprehension are held to result from a phonological mediation process. Current models of single word information processing should be considered. ${ }^{8}$ Our patient's speech output deficit (at least the "negative" symptom - that is, the anomia) may be attributed to a difficulty in accessing her intact phonological word form level from the semantic system. Evidence of a relatively undisturbed access from the visual modality to (and of the intactness of) the semantic system comes from her largely spared reading comprehension. Intactness of the semantic system is also proved by her ability to deal with semantic anomalies and to match written words to the corresponding pictures as well as to semantically related pictures. On the other hand her ability to read aloud seemed to show relatively well-preserved ability at the level of the phono- logical word form. In fact her ability to respect the proper word stress, especially in cases in which a rule-based guess would fail, appears to be an indication of a fully working phonological word form level. This finding, along with the fact that reading was fairly fluent but with some difficulty in reading non-words suggests that she did not rely completely on the print to sound conversion system. Her reading aloud may have been accomplished by a direct connection from the orthographic entries to the phonological word form.

An alternative explanation could be found in Saffran's hypothesis that lexical access may occur on the basis of partial phonological information. ${ }^{9}$ In our case the combined action of a partially disturbed print to sound conversion system and of a partially interrupted output from the semantic system might, nevertheless, succeed in activating the phonological word form; this explanation would eliminate the necessity of postulating a lexical route that bypasses the semantic system. A comparatively less disturbed access from the semantic system to the orthographical word form level seems to account for her superior written naming. Evidence for such a direct way from the semantic system to the orthographical word form level has been recently provided. ${ }^{10} \mathrm{Within}$ this picture a key question then remains about where our patient's neologisms (the positive symptom) come from. The available data seem to suggest that her neologisms may be interpreted as a difficulty in activating lexical units in the phonological word form level from the semantic system. As the semantic system cannot feed the phonological output lexicon with proper information, it seems possible that it ends by activating a set of rules normally limited to check the plausibility of phonemic sequences independently of their meaning. ${ }^{11}$

In our patient the location of the cortical areas critical for language processing seemed to be deviant from the normal pattern, suggesting a large involvement of the right hemisphere. In fact, despite her right handedness, she did not apparently become aphasic after her first left sided lesion. Although minor, subclinical aphasic symptoms may have been present at this stage, a severe aphasia as seen in the course of the present investigation should have been noticed. Instead she developed her full blown symptomatology when subsequently injured in the right hemisphere. This sequence of events may indicate the role of the nondominant hemisphere in understanding written language. A patient reported by Heilman $e t$ $a l^{12}$ although unable to repeat, name, and understand spoken language, showed a spared written language comprehension after a left hemisphere lesion that was abolished after a subsequent right sided lesion. The authors proposed that reading comprehension may be partly accomplished by the non-dominant hemisphere (for related views $\operatorname{se}^{1314}$ ). Our patient's preserved reading comprehension and reading aloud ability, persisting even after a right temporal-parietal lesion, suggests that further studies are necessary before reaching a definite conclusion on the role of the nondominant hemisphere in reading. 
1 Lecours AR, Rouillon F. Neurolinguistic analysis of jargonaphasia and jargonagraphia. Studies in Neurolinguistic 1976;2:95-144

2 Hier DB, Mohr JP. Incongruous oral and written naming. Brain Lang 1977;4:115-25.

3 Basso A, De Renzi E, Faglioni P, Scotti G, Spinnler H. Neuropsychological evidence for the existence of cerebral areas critical to the performance of intelligence tasks. Brain 1973;715-28.

4 Semenza C, Panzeri M, Re S. Eloquio spontaneo: categorie grammaticali (prospettive per la clinica dei deficit lessicagrammaticali (prospettive per la clinica dei
li). Acta Phoniatrica Latina 1989;XI:1-11.

5 Buckingham HW, Whitaker H, Whitaker HA. Alliteration and assonance in neologistic jargonaphasia. Cortex and assonance

6 De Renzi E, Faglioni P. Normative data and screening power of a shortened version of the Token Test. Cortex 1978;14:41-9.

7 Geschwind N. Disconnection syndromes in animals and man. Brain 1965;88:237-94, 585-644.
8 Ellis AW. Spelling and writing (and reading and speaking). In: Ellis AW, ed. Normality and pathology in cognitive function. London: Academic Press, 1982.

9 Saffran EM. Lexicalisation and reading performance in surface dyslexia. In: Patterson KE, Marshall JC, Coltheart M, eds. Surface dyslexia. London: Erlbaum, 1985.

10 Bub D, Kertesz A. Evidence for lexicographic processing in a patient with preserved written over oral simple word naming. Brain 1982;105:697-717.

11 Butterworth B. Hesitation and the production of verbal paraphasias and neologisms in jargon aphasia. Brain Lang paraphasias and

12 Heilman KM, Rothi L, Campanella D, Wolfson S. Wernicke's and global aphasia without alexia. Arch Neurol nicke's and global aphasia without alexia. Arch Neurol

13 Coltheart M. Deep dyslexia: a right hemisphere hypothesis. In: Coltheart M, Patterson KE, Marshall JC, eds. Deep dyslexia. London: Routledge, 1980.

14 Patterson KE, Varga Khadem F, Polkey CE. Reading with one hemisphere. Brain 1989;112:39-63. 